\title{
Behavioral Taste Similarities and Differences among Monosodium L-Glutamate and Glutamate Receptor Agonists in C57 BL Mice
}

\author{
Kiyohito NAKASHIMA $^{1, *}$, Hideo KatsuKaWA ${ }^{2}$, Kazushige SASAmoto ${ }^{3}$ \\ and Yuzo NINOMIYA ${ }^{3}$ \\ Department of ${ }^{1}$ Chemistry and ${ }^{2}$ Oral Physiology, Asahi University School of Dentistry, \\ 1851-1 Hozumi, Hozumi-cho, Motosu-gun, Gifu 501-0296, Japan \\ ${ }^{3}$ Section of Oral Neuroscience, Graduate School of Dental Sciences, Kyushu University, \\ 3-1-1 Maidashi, Higashi-ku, Fukuoka 812-8582, Japan
}

(Received November 30, 2000)

\begin{abstract}
Summary Monosodium L-glutamate (MSG) and 5'-ribonucleotides elicit umami taste in humans and probably in some species of animals. Previous studies suggest that tastemGluR4 and NMDA receptor may be involved in taste transduction for umami, but behavioral responses in rats do not support the involvement of NMDA receptor. In the present study, behavioral similarities and differences among MSG, mGluR4 agonist $\mathrm{L}(+)$-2-amino4-phosphonobutyrate (L-AP4), and NMDA receptor agonist N-methyl-D-aspartate (NMDA) were compared in C57BL mice by using a conditioned taste aversion paradigm. Mice conditioned to avoid either MSG or $10 \mathrm{mM} \mathrm{L-AP4}$ appeared to avoid MSG, disodium 5'-inosinate (IMP), a mixture of MSG and IMP, and L-AP4, but not NMDA. Aversive conditioning to either sucrose or NMDA was generalized only to a mixture of MSG+IMP or NaCl. However, aversive conditioning to L-AP4 at $1 \mathrm{~mm}$ was generalized to NMDA and the umami substances. Lick rates for L-AP4 increased by mixing with (RS)- $\alpha$-cycloprophy-4-phosphonophenylglycine (mGluR4 antagonist) when animals were conditioned to avoid MSG or LAP4. Lick rates for NMDA also either decreased or increased by mixing with glycine (NMDA receptor coagonist) or $\mathrm{D}(-)$-2-amino-5-phosphonopentanoic acid (NMDA receptor antagonist) when animals were conditioned to avoid L-AP4 or NMDA. In sucrose-conditioned mice, gurmarin (a sweet inhibiting peptide) suppressed the avoidance of sucrose and a mixture of MSG and IMP, but not L-AP4 and NMDA. The results suggest the possibility that to C57BL mice MSG may taste similar to L-AP4 but different from NMDA, although both types of glutamate receptors as well as gurmarin-sensitive sweet receptor may be involved in perception of umami taste.
\end{abstract}

Key Words monosodium L-glutamate, $\mathrm{L}(+)$-2-amino-4-phosphonobutyrate, $\mathrm{N}$-methyl-Daspartate, conditioned taste aversion paradigm, mice

Monosodium L-glutamate (MSG) and 5'-ribonucleotides such as disodium $5^{\prime}$-inosinate (IMP) and disodium $5^{\prime}$-guanylate (GMP) are widely distributed in natural foods (1). In humans and probably in certain species of animals, MSG and 5'-ribonucleotides elicit umami, the fifth basic taste distinct from sweet, salty, sour, and bitter tastes. The most conspicuous feature of umami is a synergism, indicating the magnitude of umami for a mixture of MSG and 5'-ribonucleotide is far more than the sum of each component.

Previous electrophysiological studies have proposed that taste responses to MSG may be mediated at least partially through $\mathrm{Na}^{+}$channels sensitive to amiloride and sweet receptors sensitive to both pronase E, a proteolytic enzyme, and gurmarin, a plant peptide isolated from Gymnema sylvestre (2). Pronase E, entire sweet response inhibitor in rats and mice $(3,4)$, partially suppresses the chorda tympani (CT) nerve response to MSG and a mixture of MSG and IMP in mice (2). Gurmarin

*E-mail: nakakiyo@dent.asahi-u.ac.jp almost completely suppresses the CT nerve responses to sucrose and a mixture of MSG and IMP in rats $(5,6)$. In contrast, in C57BL mice, sweetener responses of the CT nerve are suppressed by gurmarin to $-50 \%$ of control response ( 7$)$ and recovered by $\beta$-cyclodextrin $(\beta$-CD) $(8)$, whereas suppressive effects of gurmarin is minimal in the glossopharyngeal (GL) nerve (9). In C57BL mice, gurmarin has also been shown to partially suppress the CT, but not the GL nerve responses to MSG and a mixture of MSG and IMP (2).

More recently, molecular, electrophysiological, and behavioral studies have also proposed the involvement of at least two types of glutamate receptors: group III metabotropic receptor (mGluR4) and ionotropic (NMDA) receptor. Evidence for the possible involvement of mGluR4 initially derives from studies showing expression of mGluR4 specifically in rat taste buds and behavioral taste similarity among MSG and L(+)-2amino-4-phosphonobutyrate (L-AP4), an agonist for mGluR4 (10). Electrophysiological studies with isolated taste cells have also shown that L-AP4 mimics the hy- 
perpolarizing response elicited by $\operatorname{MSG}(11,12)$, and that a mGluR4 antagonist (RS)- $\alpha$-cyclopropyl-4-phosphonophenylglycine (CPPG) suppresses hyperpolarizing response elicited by L-AP4 (12). Recordings of the CT nerve responses also showed synergistic interaction to a mixture of L-AP4 and IMP or N-methyl-D-aspartate (NMDA, NMDA receptor agonist) and IMP (2). Furthermore, recent molecular studies have succeeded in cloning a variant form of brain-mGluR4 (tastemGluR4) from rat taste buds and in functional characterization of the receptor expressed in CHO cells (13).

Possible involvement of NMDA receptor in taste transduction for umami has been suggested by the findings that MSG and NMDA activate a cation conductance in membrane vesicles from mouse tongue incorporated into bilayers $(14,15)$. Calcium ${ }^{2+}$ imaging studies also showed MSG- and NMDA-induced increase in intracellular $\mathrm{Ca}^{2+}$ concentration in isolated mouse taste cells (16). In addition, whole cell recordings of isolated rat fungiform taste cells have shown that NMDA elicits depolarizing response with either enhancement by glycine (NMDA receptor coagonist) or suppression by $\mathrm{D}(-)$-2-amino-5-phosphonophenylglycine (NMDA receptor antagonist, D-AP5) (12). However, recent behavioral studies in rats suggest that the taste of MSG may be different from NMDA (17), and that a combination of NMDA and IMP, but not L-AP4 and IMP, does not result in a synergism (18).

The C57BL mouse is reported to show high behavioral discriminabilities between MSG and the four basic substances as compared with rats (6), hamsters (19) and other strains of mice $(20-23)$. However, there is no available data on their behavioral responses to L-AP4 and NMDA, although their taste nerve responses have partially been analyzed (2). In the present study, therefore, we compared taste similarities and differences among MSG, L-AP4, and NMDA using a conditioned taste aversion paradigm in C57BL mice.

\section{MATERIALS AND METHODS}

Animals and stimuli. Animals were male or female C57BL/6 mice, weighing 18-25 g. Each animal was conditioned to avoid one of 5 compounds and distilled water, consisting of 5 experimental groups and one control group of 4-8 mice each. Three to four animals in each group were housed together and maintained on ad libitum food, but given access only to distilled water during the training and testing sessions.

The conditioning stimulus for each of the 5 experimental groups was one of the following: $30 \mathrm{~mm}$ MSG, 1 or $10 \mathrm{~mm}$ L-AP4 (Sigma Chemical Co., St Louis, MO, USA), $0.1 \mathrm{~m}$ sucrose or $50 \mathrm{~mm}$ NMDA (Nacalai Tesque, Inc., Kyoto, Japan) dissolved in distilled water. The conditioned stimulus for the control group was distilled water. Test stimuli used were as follows: $0.01-0.1 \mathrm{M} \mathrm{su}-$ crose (Suc), $0.1 \mathrm{M} \mathrm{NaCl}, 1 \mathrm{~mm} \mathrm{HCl,} 0.1 \mathrm{~mm}$ quinine hydrochloride (Qui), 0.03-0.1 M MSG, $0.3 \mathrm{~mm}$ IMP, 0.001-0.1 M MSG+0.3 mM IMP, 0.01-10 mM L-AP4, $0.1 \mathrm{~mm}$ L-AP4+1 mM CPPG (Tocris Cookson, Bristol, UK), 0.01-50 mM NMDA, $10 \mu \mathrm{M}$ glycine (Gly), 0.01-
$10 \mathrm{~mm} \mathrm{NMDA}+10 \mu \mathrm{M}$ Gly, $1 \mathrm{~mm} \mathrm{NMDA}+50 \mu \mathrm{M}$ D-AP 5 (Tocris Cookson), and $10 \mathrm{~mm}$ NMDA +0.5 mM D-AP5. Solutions containing L-AP4, NMDA, CPPG or D-AP5 were titrated to $\mathrm{pH} 6.0-7.0$ with $4 \mathrm{~N}-\mathrm{NaOH}$ to avoid potential complication elicited by acid taste.

Procedures. Experimental protocols for a conditioned taste aversion paradigm were essentially same to that of Ninomiya and Funakoshi (22). Briefly, each animal was placed in a test box on day 1 of training and given free access to distilled water during a 1-h session. Lick rates were measured by a lickometer with a laser beam lick sensor (Yutaka Electronics Co., Gifu, Japan) and recorded on a pen recorder. From days 2-5, training session time was reduced from $1 \mathrm{~h}$ to $30 \mathrm{~min}$. During this period, the animal was trained to drink distilled water on an interval schedule, consisting of 10-s periods of presentation of the distilled water alternated with 20-s inter-trial intervals, resulting in 30-50 trials during the 30-min session. On day 6, each animal was given access to one of the five conditioning stimuli during the interval schedule for more than 20 trials, and then given an intraperitoneal injection of $\mathrm{LiCl}$ $(230 \mathrm{mg} / \mathrm{kg})$ to induce gastrointestinal malaise. Control mice drank distilled water before the $\mathrm{LiCl}$ injection. The seventh day was a recovery period, but the training of drinking distilled water for $30 \mathrm{~min}$ was still carried out on this day. On days 8-10, lick rates for $10 \mathrm{~s}$ were measured for each test stimuli and distilled water. Lick rates were also measured before and after treatment of the tongue with $30 \mu \mathrm{g} / \mathrm{mL}$ gurmarin for $10 \mathrm{~min}$, and after treatment of the tongue with $15 \mathrm{~mm} \beta$-CD (Tokyo Chemical Industry Co., Tokyo, Japan) for $10 \mathrm{~min}$. Gurmarin and $\beta$-CD were dissolved in $5 \mathrm{~mm}$ phosphate buffer, $\mathrm{pH}$ 6.8. The mean lick rate across days 8-10 was obtained for each of the test solutions in each animal.

The behavioral data were quantified by expressing them as a percent suppression score based on the ratio of the lick rate to each taste stimulus given by an experimental group to that of the control group, as shown by the following formula: percent suppression $=[1-$ (lick rate of experimental group/lick rate of control group) $] \times 100$. Statistical analysis was Student's $t$-test.

\section{RESULTS}

\section{Conditioning to MSG, L-AP4 or NMDA}

Figure 1 shows patterns of suppression of licking across 7 taste stimuli after the mice were conditioned to avoid $30 \mathrm{~mm}$ MSG, $10 \mathrm{mM} \mathrm{L-AP4,} 0.1 \mathrm{M}$ sucrose or $50 \mathrm{~mm}$ NMDA. The dark columns indicate that lick rate after conditioning was statistically significantly smaller than that in the control group ( $p<0.05-0.01, t$-test). The generalization pattern was similar between the $30 \mathrm{~mm}$ MSG and $10 \mathrm{~mm}$ L-AP4 groups. These animals avoided $30 \mathrm{~mm}$ MSG, $0.3 \mathrm{~mm}$ IMP, a mixture of $30 \mathrm{~mm}$ MSG and $0.3 \mathrm{~mm}$ IMP, and $10 \mathrm{~mm} \mathrm{~L}-\mathrm{AP} 4$, but not $0.1 \mathrm{M}$ $\mathrm{NaCl}, 1 \mathrm{~mm} \mathrm{HCl}, 0.1 \mathrm{~mm}$ quinine hydrochloride and $10 \mathrm{~mm}$ NMDA. Aversive conditioning to either $0.1 \mathrm{M} \mathrm{su}-$ crose or $50 \mathrm{~mm}$ NMDA was generalized only to a mixture of $30 \mathrm{~mm} \mathrm{MSG}$ and $0.3 \mathrm{~mm}$ IMP or to $0.1 \mathrm{M} \mathrm{NaCl}$. However, aversive conditioning to $\mathrm{L}-\mathrm{AP} 4$ at $1 \mathrm{~mm}$ was 

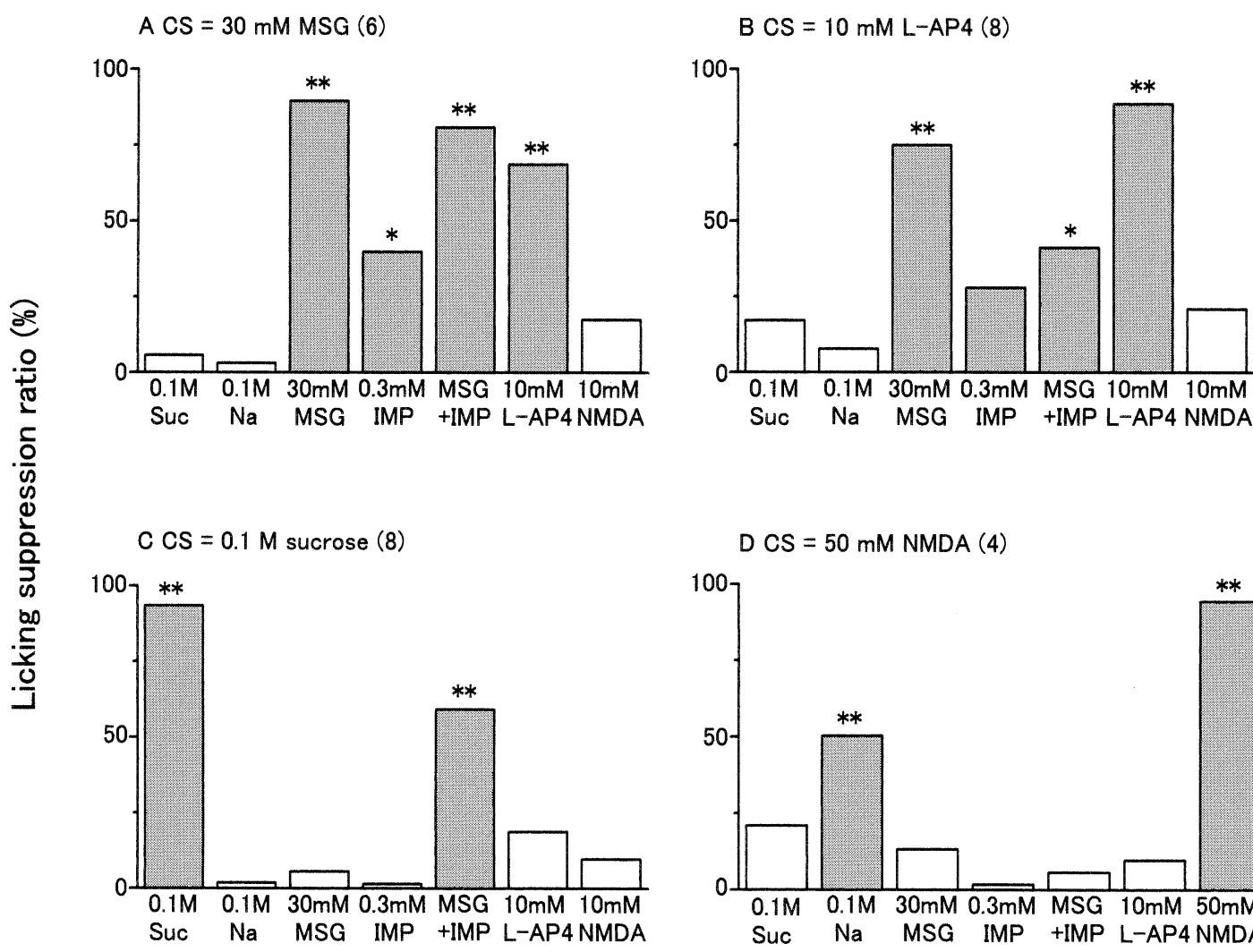

Fig. 1. Patterns of suppression of licking across various taste stimuli after aversions were conditioned in C57BL mice to $30 \mathrm{~mm}$ MSG (A), $10 \mathrm{~mm}$ L-AP4 (B), $0.1 \mathrm{~m}$ sucrose (C) or $50 \mathrm{~mm}$ NMDA (D). The number of mice used in each group is shown in parentheses. The dark columns indicate that lick rate after conditioning with each taste stimulus was statistically significantly smaller than that in the controls conditioned with distilled water $\left(t\right.$-test, $\left.{ }^{* *}: p<0.01,{ }^{*}: p<0.05\right)$. Suc, sucrose; Na, NaCl; Qui, quinine hydrochloride; MSG, monosodium L-glutamate; IMP, disodium 5'-inosinate; L-AP4, L(+)2-amino-4-phosphonobutyrate; NMDA, N-methyl-D-aspartate.

generalized to $0.01-10 \mathrm{~mm}$ NMDA as well as a mixture of 0.1 M MSG and 0.3 mM IMP (data not shown).

Effects of mGluR4 antagonist on behavioral responses

After acquisition of learned aversion either to $30 \mathrm{~mm}$ MSG (Fig. 2A) or $10 \mathrm{~mm} \mathrm{L-AP4}$ (Fig. 2B), lick rates for $0.1 \mathrm{~mm}$ L-AP4 increased to statistically significant levels by mixing it with $1 \mathrm{~mm}$ CPPG $(p<0.001, t$-test $)$. Similar antagonism by $1 \mathrm{mM}$ CPPG was also observed when $1 \mathrm{~mm}$ L-AP4 was used as a conditioning stimulus $(p<0.001, t$-test, data not shown).

Effects of NMDA receptor coagonist and antagonist on behavioral responses

Aversive conditioning of $10 \mathrm{~mm}$ L-AP4 did not generalize to $0.01-10 \mathrm{~mm}$ NMDA, but generalized to mixtures of NMDA with $10 \mu \mathrm{M}$ glycine $((p<0.01-0.001, t$ test, Fig. 3A). Glycine at $10 \mu \mathrm{m}$ also augmented an aversion to $0.01-10 \mathrm{~mm}$ NMDA in $50 \mathrm{~mm}$ NMDA-conditioned mice (Fig. 3C).

When animals were conditioned to avoid $1 \mathrm{mM} \mathrm{L-}$ AP4, lick rates for $1 \mathrm{~mm}$ NMDA increased to a statistically significant level when it was mixed with $50 \mu \mathrm{M}$ DAP5 $(p<0.001, t$-test, Fig. 3B). Such an antagonism was also observed at $0.5 \mathrm{~mm}$ D-AP 5 in lick rates for $10 \mathrm{~mm}$ NMDA when mice were conditioned to avoid 50 mm NMDA ( $p<0.001, t$-test, Fig. 3C).

Gurmarin inhibition of a synergism

Figure 4 shows the effects of gurmarin and $\beta$-CD on
A $C S=30 \mathrm{mM} \mathrm{MSG}(6)$

B CS $=10 \mathrm{mM} \mathrm{L-AP4} \mathrm{(8)}$
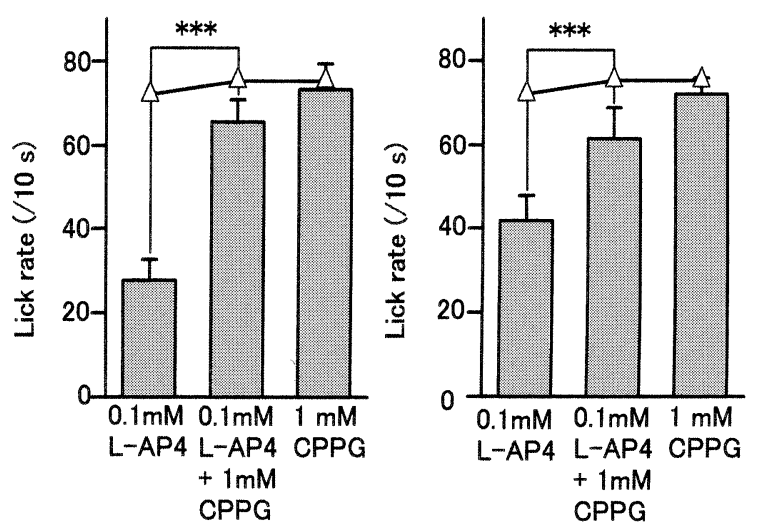

Fig. 2. Effects of (RS)- $\alpha$-cyclopropyl-4-phosphonophenylglycine (mGluR4 antagonist) on the lick rates for $0.1 \mathrm{~mm}$ L-AP4 when C57BL mice were conditioned to avoid $30 \mathrm{~mm}$ MSG (A) or $10 \mathrm{~mm} \mathrm{~L}-\mathrm{AP} 4$ (B). CPPG, (RS)- $\alpha$-cyclopropyl-4-phosphonophenylglycine. The mean lick rates for controls conditioned with distilled water are indicated by open triangles. The number of mice used in each group is shown in parentheses. Mean \pm SE. ${ }^{* * *}: p<0.001$ (t-test).

the lick rates for various taste stimuli when mice were conditioned to avoid $0.1 \mathrm{~m}$ sucrose. Lick rates for 30-100 mm sucrose and mixtures of 10-300 mM MSG 
A CS $=10 \mathrm{mM} \mathrm{L}-\mathrm{AP} 4(8)$

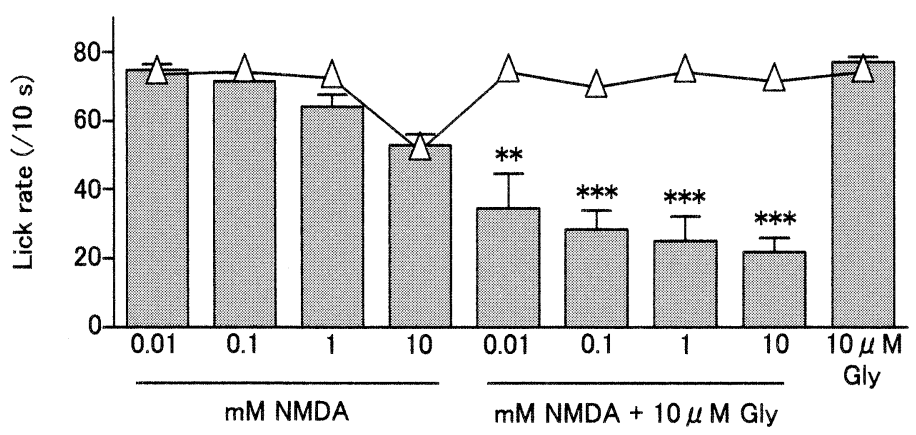

$\mathrm{B} C S=1 \mathrm{mM} \mathrm{L}-\mathrm{AP} 4(6)$

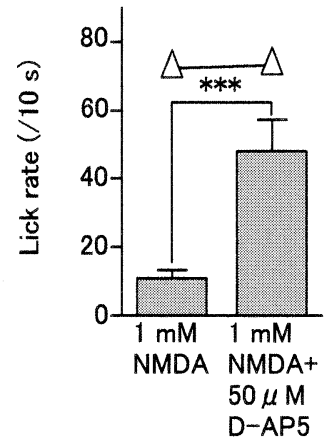

C $\mathrm{CS}=50 \mathrm{mM}$ NMDA (4)

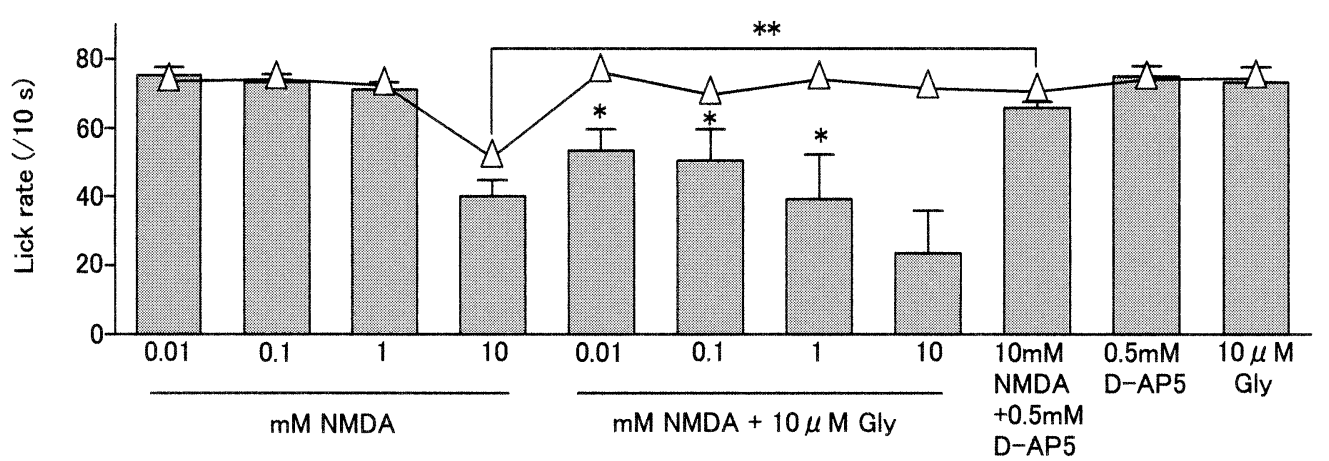

Fig. 3. Effects of glycine (NMDA receptor coagonist) and D(-)-2-amino-5-phosphonopentanoic acid (NMDA receptor antagonist) on the lick rates for various taste stimuli when C57BL mice were conditioned to avoid $10 \mathrm{~mm}(\mathrm{~A})$ or $1 \mathrm{~mm}(\mathrm{~B}) \mathrm{L}-$ AP4 or 50 mM NMDA (C). The mean lick rates for controls conditioned with distilled water are indicated by open triangles. The number of mice used in each group is shown in parentheses. Gly, glycine; D-AP5, D(-)-2-amino-5-phosphonopentanoic acid. Mean \pm SE. ${ }^{* * *}: p<0.001,{ }^{* *}: p<0.01,{ }^{*}: p<0.05$ (t-test).

and $0.3 \mathrm{~mm}$ IMP statistically significantly increased by treatment of the tongue with $30 \mu \mathrm{g} / \mathrm{mL}$ gurmarin $(p<0.05-0.001, t$-test $)$. When the tongue was subsequently rinsed with $15 \mathrm{~mm} \beta-\mathrm{CD}$, lick rates for 30-100 mu sucrose and mixtures of 10-100 mM MSG and $0.3 \mathrm{~mm}$ IMP recovered to levels about $15-50 \%$ of those obtained after gurmarin ( $p<0.05-0.001, t$-test). However, none of the lick rates for $0.1 \mathrm{M} \mathrm{NaCl}, 1 \mathrm{~mm}$ $\mathrm{HCl}, 0.1 \mathrm{~mm}$ quinine hydrochloride, $10 \mathrm{~mm} \mathrm{~L}-\mathrm{AP} 4$, or 10 mM NMDA were affected by treatment of the tongue with gurmarin or $\beta$-CD (data not shown).

\section{DISCUSSION}

The present results in mice clearly show that an aversive conditioning to sucrose is generalized to a mixture of MSG and IMP. The results also show that generalization to a mixture of MSG and IMP is suppressed by gurmarin and recovered by $\beta$-CD. These findings confirm and extend previous behavioral and electrophysiological studies in rats and mice. In rats, sucrose behaviorally mimics the taste of MSG when amiloride is added to suppress $\mathrm{Na}^{+}$response $(6,10)$. Electrophysiological studies in rats (24) and mice (23) have shown that CT nerve fibers sensitive to MSG also respond either to $\mathrm{NaCl}$ or sucrose, and that some fibers showing a synergism are sensitive predominantly to sucrose. Pronase E has also been shown to suppress CT nerve responses to MSG and a mixture of MSG and GMP in C57BL mice to $72.6 \%$ and $43 \%$ of control, respectively (2). In rats, gur-

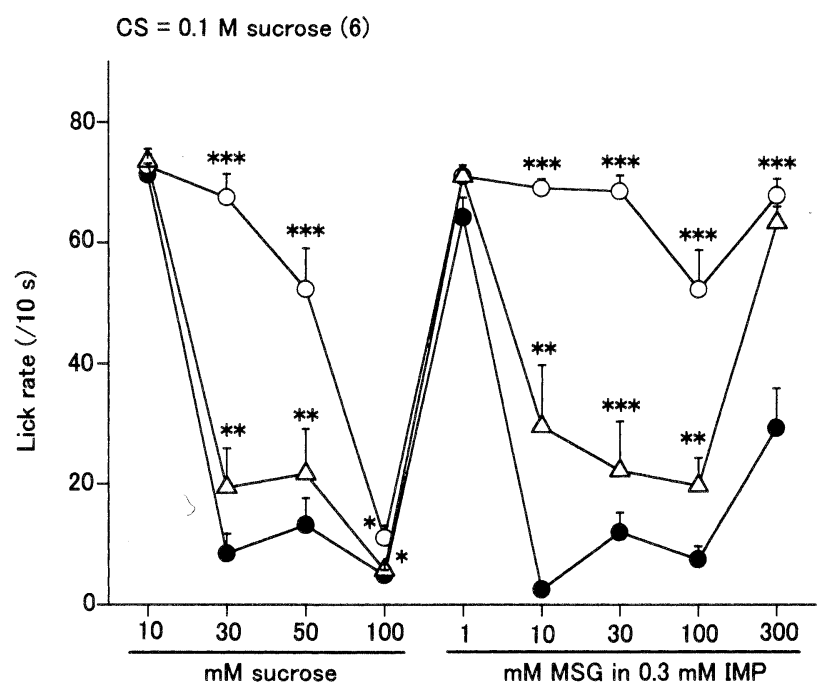

Fig. 4. Effects of treatment of the tongue with $30 \mu \mathrm{g} / \mathrm{mL}$ gurmarin and $15 \mathrm{~mm} \beta$-CD on the lick rates to various taste stimuli when C57BL mice were conditioned to avoid $0.1 \mathrm{~m}$ sucrose. The number of mice used is shown in parenthesis. Lick rates are indicated by closed circles before gurmarin, open circles after gurmarin, and by open triangles after $\beta$-CD. Statistically significantly different between control and after gurmarin or between before and after $\beta$-CD. Mean \pm SE. ${ }^{* * *}: p<0.001,{ }^{* *}: p<0.01,{ }^{*}: p<0.05$ ( $t$ test). 
marin completely suppressed CT nerve responses to a mixture of MSG and IMP dissolved in amiloride solution (6). In contrast in C57BL mice, gurmarin suppressed CT nerve responses to a mixture of MSG and IMP to $-65 \%$ of control, while it did not affect GL nerve responses to any of the taste stimuli, including umami substances (2). Taken together, these findings suggest that umami substances may stimulate gurmarin-sensitive sweet receptors of rat taste cells in the fungiform and a portion of the foliate papillae (innervated by the CT nerve). The findings also suggest that in C57BL mice responses to umami substances may be mediated through both gurmarin-sensitive sweet receptors and non-sweet receptor mechanisms of taste cells innervated by the CT nerve but through only the latter mechanisms of those in the vallate and foliate papillae (innervated by the GL nerve).

MSG- or L-AP4-conditioned C57BL mice exhibited aversion to solutions of MSG, IMP, a mixture of MSG and IMP, and L-AP4. Conditioning of MSG dissolved in amiloride solution in rats also resulted in aversion to a solution of L-AP4 (10). These data suggest that to mice and rats MSG may taste similar to L-AP4. Whole cell patch-clamp recordings of rat fungiform taste cells showed that hyperpolarizing responses elicited by LAP4 were suppressed by the mGluR4 antagonist CPPG (12). Although not all experiments using isolated taste cells can exclude the possibility that bath-applied stimulant may act at either the apical or the basolateral membrane of taste cells, our behavioral data clearly show that the site of an antagonism between L-AP4 and CPPG is on the apical membrane of taste cells. Consistently, behavioral responses in rats $(18)$ and the CT nerve responses in C57BL mice (2) showed a synergistic interaction between L-AP4 and IMP. In C57BL mice, the synergistic responses in the CT nerve were insensitive to both pronase and gurmarin (2). In addition, a threshold for L-AP4 was $30 \mu \mathrm{M}$ for taste-mGluR4 expressed in CHO cells (13), while a similar threshold $(10 \mu \mathrm{M})$ was obtained in behavioral response in C57BL mice. These findings suggest that taste transduction for umami may be mediated in part through L-AP4-sensitive tastemGluR4.

Aversive conditioning to NMDA in C57BL mice is generalized to $\mathrm{NaCl}$, but not to the other taste qualities, including umami. Similarly, MSG- or $10 \mathrm{~mm}$ L-AP4-conditioned mice display no aversion to solutions of NMDA. In rats, conditioning to MSG dissolved in amiloride solution did not result in aversion to $\operatorname{NMDA}(10,17)$. These results suggest that both mice and rats may find the taste of NMDA quite different from that of MSG. However, conditioning to L-AP4 at $1 \mathrm{~mm}$ in C57BL mice is generalized to NMDA. In addition, avoidance of NMDA in $1 \mathrm{mM} \mathrm{L-AP4-} \mathrm{or} \mathrm{NMDA-conditioned} \mathrm{mice} \mathrm{is} \mathrm{ei-}$ ther enhanced or suppressed by mixing it with glycine or D-AP5. Whole cell patch-clamp recordings of rat fungiform taste bud cells (12) have also shown that NMDA receptors share some properties with their brain form (25), such as co-activation by glycine and suppression by D-AP5. Although behavioral studies in rats showed no synergism between NMDA and IMP (18), the CT nerve in C57BL mice showed synergistic responses to the mixture (2). In addition, several types of NMDA receptors were detected in rat lingual tissues (10). Collectively, these data suggest that NMDA receptors located on the apical membrane of taste cells may be involved in taste transduction for umami in both mice and rats.

Taste sensitivity to the umami substances in mice has been shown to be dependent on the strain, the taste nerves, and on age. Magnitudes of the synergism in the $\mathrm{CT}$ responses are greater in the order of $\mathrm{C} 3 \mathrm{H}>$ C 57BL $>$ BALB mice (20). Taste information conveyed by the GL nerve fibers plays a relatively more important role in the qualitative discrimination between MSG and the four basic taste substances (21-23). Expression of mGluR4 in the vallate and foliate taste buds is higher in pre-weanling rats compared with adult rats $(10)$, corresponding to greater responses of the GL nerve to MSG in juvenile mice (26). We are now on the way to examine if and to what extent such a difference in sensitivity to the umami substances would be reflected in behavioral responses.

In summary, the present results together with previous findings support the idea that both taste-mGluR4 and NMDA receptor as well as amiloride-sensitive $\mathrm{Na}^{+}$ channel and gurmarin-sensitive sweet receptor may be involved in taste transduction for umami substances in C57BL mice.

\section{Acknowledgements}

This work was supported in part by a grant from Miyata, Asahi University (1999) (K. Nakashima), Grants-in-Aid 9557147 (Y. Ninomiya) and 12470394 (Y. Ninomiya) from the Ministry of Education, Science, Sport, and Culture of Japan, and Grant of Program for Promotion of Basic Research Activities for Innovative Bioscience from Bio-Oriented Technology Research Advancement Institution. Gurmarin was kindly provided by Dr. T. Imoto, Tottori University.

\section{REFERENCES}

1) Ninomiya K. 1998. Natural occurrence. In: Food Reviews International (Teranishi R, Hornstein I, Engel K-H, eds), Vol 14, p 177-211. Marcel Dekker, New York.

2) Ninomiya $Y$, Nakashima $K$, Fukuda A, Nishino $H$, Sugimura T, Hino A, Danilova V, Hellekant G. 2000. Responses to umami substances in taste bud cells innervated by the chorda tympani and glossopharyngeal nerves. J Nutr 130: 950S-953S.

3) Hiji Y. 1975. Selective elimination of taste responses to sugars by proteolytic enzymes. Nature 256: 427-429.

4) Ninomiya Y, Nomura T, Katsukawa H. 1992. Genetically variable taste sensitivity to D-amino acids in mice. Brain Res 596: 349-352.

5) Imoto T, Miyasaka A, Ishima R, Akasaka K. 1991. A novel peptide isolated from the leaves of Gymnema sylvestre-I. Characterization and its suppressive effect on the neural responses to sweet taste stimuli in the rat. Comp Biochem Physiol 100A: 309-314.

6) Yamamoto T, Matsuo R, Fujimoto Y, Fukunaga I, Miyasaka A, Imoto T. 1991. Electrophysiological and 
behavioral studies on the taste of umami substances in the rat. Physiol Behav 49: 919-925.

7) Ninomiya Y, Imoto T. 1995. Gurmarin inhibition of sweet taste responses in mice. Am J Physiol 268: R1019-R1025.

8) Ninomiya Y, Inoue M, Imoto T. 1998. Reduction of the suppressive effects of gurmarin on sweet taste responses by addition of beta-cyclodextrin. Chem Senses 23: 303-307.

9) Ninomiya Y, Inoue M, Imoto T, Nakashima K. 1997. Lack of gurmarin sensitivity of sweet taste receptors innervated by the glossopharyngeal nerve in C57BL mice. Am J Physiol 272: R1002-R1006.

10) Chaudhari N, Yang H, Lamp C, Delay E, Cartford C, Than T, Roper S. 1996. The taste of monosodium glutamate: membrane receptors in taste buds. J Neurosci 16: 3817-3826.

11) Bigiani A, Delay RJ, Chaudhari N, Kinnamon SC, Roper SD. 1997. Responses to glutamate in rat taste cells. J Neurophysiol 77: 3048-3059.

12) Lin W, Kinnamon SC. 1999. Physiological evidence for ionotropic and metabotropic glutamate receptors in rat taste cells. J Neurophysiol 82: 2061-2069.

13) Chaudhari N, Landin AM, Roper SD. 2000. A metabotropic glutamate receptor variant functions as a taste receptor. Nat Neurosci 3: 113-119.

14) Brand JG, Teeter JH, Kumazawa T, Huque T, Bayley DL. 1991. Transduction mechanisms for the taste of amino acids. Physiol Behav 49: 899-904.

15) Teeter JH, Kumazawa T, Brand JG, Kalinoski DL, Honda E, Smutzer G. 1992. Amino acid receptor channels in taste cells. Soc Gen Physiol Ser 47: 291-306.

16) Hayashi Y, Zviman MM, Brand JG, Teeter JH, Restrepo D. 1996. Measurement of membrane potential and $\left[\mathrm{Ca}^{2+}\right]_{\mathrm{i}}$ in cell ensembles: application to the study of glutamate taste in mice. Biophys J 71: 1057-1070.

17) Stapleton JR, Roper SD, Delay ER. 1999. The taste of monosodium glutamate (MSG), L-aspartic acid, and Nmethyl-D-aspartate (NMDA) in rats: are NMDA receptors involved in MSG taste? Chem Senses 24: 449-457.

18) Delay ER, Beaver AJ, Wagner KA, Stapleton JR, Harbaugh JO, Catron KD, Roper SD. 2000. Taste preference synergy between glutamate receptor agonists and inosine monophosphate in rats. Chem Senses 25: 507-515.

19) Yamamoto T, Matsuo R, Kiyomitsu Y, Kitamura R. 1988. Taste effects of 'umami' substances in hamsters as studied by electrophysiological and conditioned taste aversion techniques. Brain Res 451: 147-162.

20) Ninomiya Y, Kurenuma S, Nomura T, Uebayashi H, Kawamura H. 1992. Taste synergism between monosodium glutamate and $5^{\prime}$-ribonucleotide in mice. Comp Biochem Physiol 101A: 97-102.

21) Ninomiya Y, Funakoshi M. 1987. Qualitative discrimination among umami and the four basic taste substances in mice. In: Umami: A Basic Taste (Kawamura Y, Kare MR, eds), p 365-385. Mercel Dekker, New York.

22) Ninomiya Y, Funakoshi M. 1989. Behavioral discrimination between glutamate and the four basic taste substances in mice. Comp Biochem Physiol 92A: 365-370.

23) Ninomiya Y, Funakoshi M. 1989. Peripheral neural basis for behavioural discrimination between glutamate and the four basic taste substances in mice. Comp Biochem Physiol 92A: 371-376.

24) Sato M, Yamashita S, Ogawa H. 1970. Potentiation of gustatory response to monosodium glutamate in rat chorda tympani fibers by addition of $5^{\prime}$-ribonucleotides. Jpn J Physiol 20: 444-464.

25) Moriyoshi K, Masu M, Ishii T, Shigemoto R, Mizuno N, Nakanishi S. 1991. Molecular cloning and characterization of the rat NMDA receptor. Nature 354: 31-37.

26) Ninomiya $Y$, Tanimukai $T$, Yoshida S, Funakoshi M. 1991. Gustatory neural responses in preweanling mice. Physiol Behav 49: 913-918. 